\title{
Smoking and quitting smoking during pregnancy: A qualitative exploration of the socio-cultural context for the development of a couple-based smoking cessation intervention in Romania
}

\author{
Alexandra Brinzaniuc ${ }^{1,2}$, Andreea Strilciuc ${ }^{1,2}$, Oana M. Blaga ${ }^{1,2}$, Razvan M. Chereches ${ }^{1,2}$, Cristian I. Meghea ${ }^{1,3}$
}

\begin{abstract}
INTRODUCTION Smoking during pregnancy has negative effects on the mother and the unborn infant. Barriers to and facilitators of smoking cessation during pregnancy are context-dependent and multifaceted. This qualitative research explored pregnant women's experiences with smoking and cessation in Romania, and informed the development of a couple-focused smoking cessation intervention.

METHODS Semi-structured, in-depth interviews were conducted via telephone, with 15 pregnant women who smoked during pregnancy or had quit smoking upon learning about the pregnancy or shortly before. A hybrid inductive-deductive approach to thematic analysis was used, to identify patterns in the data and explore women's narratives, in relation to smoking and smoking cessation.

RESULTS Three main themes emerged from the data, which shaped the socio-cultural adaptation of the intervention to the local context: 1) Access to and mixed messages from the healthcare system that describe an inconsistent discourse from the healthcare system regarding smoking during pregnancy with some physicians not emphasizing the need for cessation, 2) Cessation as individual or team effort with variations in partner dynamics and difficulty in quitting that have important roles in perceptions about team efforts, and 3) Transition to motherhood and motivation to quit for the health of the pregnancy and infant, although in isolated cases women felt less connected with the pregnancy and such motivators.

CONCLUSIONS Pregnant women in Romania face systemic, interpersonal, and individuallevel barriers that can be responsively integrated in smoking cessation interventions, by culturally adapting them to the local context.
\end{abstract}

AFFILIATION

1 Department of Public Health, College of Political, Administrative and Communication Sciences, Babeș-Bolyai University, ClujNapoca, Romania 2 Center for Health Policy and Public Health, College of Political, Administrative and Communication Sciences, Babeș-Bolyai University, Cluj-

Napoca, Romania

3 Department of Obstetrics, Gynecology and Reproductive Biology, College of Human Medicine, Michigan State University, East Lansing, USA

CORRESPONDENCE TO Oana M. Blaga. Department of Public Health, College of Political, Administrative and Communication Sciences, Babes-Bolyai University ClujNapoca, 7 Pandurilor Street, 400376, Romania. E- mail: oana. blaga@publichealth.ro

\section{KEYWORDS}

smoking, smoking cessation, couple, qualitative study, barriers, Romania

Received: 12 September 2017

Revised: 1 February 2018

Accepted: 2 March 2018

\section{INTRODUCTION}

Smoking during pregnancy has significant negative effects on both the mother and the unborn infant ${ }^{1-6}$. The smoking gap across genders has been closing steadily in Central and Eastern Europe, with women smoking rates increasing significantly over the past 20 years $^{7}$. Compared to other parts of Europe, pregnant women from Eastern Europe are twice as 
likely to smoke over 10 cigarettes per $\mathrm{day}^{8}$. Evidence from Romania suggests that approximately half of the women who smoke report quitting during pregnancy, with $15 \%$ of all pregnant women continuing to smoke throughout pregnancy ${ }^{9}$. Barriers to and facilitators of smoking cessation during pregnancy are multifaceted ${ }^{10}$. Studies describe the experiences of women as being fluid and context-dependent, and these can act as both facilitators of and barriers to smoking cessation ${ }^{11}$. Qualitative studies across diverse socio-cultural environments are essential in understanding smoking behavior in the context in which it occurs, to support smoking cessation interventions.

Meta-ethnographies, including multiple qualitative studies conducted in high-income countries, identified some common themes across the smoking experiences of women that influence smoking cessation such as: degree of smoking being ingrained in their lives and the changes induced by the pregnancy; perceived benefits of cutting down compared to the costs of complete cessation; motivation to suspend smoking for the pregnancy but not necessarily to quit smoking; and the dynamics with the partner broadly and related to smoking cessation particularly ${ }^{12}$. In addition, the psychological wellbeing of women, their relationship with family, friends and health professionals, the evaluation of the risk of smoking and their changing connection with smoking, are identified as factors in the process of quitting smoking ${ }^{10}$.

This qualitative research was conducted to inform the development of a couple-focused smoking cessation intervention during pregnancy in Romania (the Quit Together program) ${ }^{13}$. Briefly, the intervention consists of motivation-enhancing telephone counseling; it builds on the Motivation and Problem Solving Approach (MAPS) ${ }^{14}$, and thus it includes building skills to solve problems that may arise during smoking cessation. Studies suggest significant changes in smoking trends in post-communist Central and Eastern European countries, with increased initiation among women ${ }^{15}$ that needs to be explored in depth. Existing evidence also suggests high pregnancy smoking prevalence in Romania and other neighboring countries ${ }^{9}$, significantly higher compared to developed countries. Thus, an in-depth understanding of the context of smoking and cessation is essential, to develop and culturally adapt the intervention, given the limited information available within the Romanian socio-cultural environment (a middleincome former communist country).

\section{METHODS}

We conducted semi-structured in-depth interviews via telephone, with 15 pregnant women who had quit smoking upon learning about the pregnancy or shortly before, or continued smoking during pregnancy. In order to ensure reporting consistency, the Consolidated Criteria for Reporting Qualitative Research (COREQ) was used in drafting the manuscript and reporting the results. COREQ is described in detail elsewhere ${ }^{16}$.

\section{Recruitment and screening procedures}

Women were approached in the waiting rooms of two State-owned obstetrics and gynecology clinics, and two general practitioner (GP) offices, in ClujNapoca, Romania. Trained research assistants (in the clinics) and GPs (in GP practices) explained the study objectives and procedures, and invited women to participate by signing a consent form for contact. Pregnant women were considered eligible if they were 18 years of age or older, were current smokers or had quit smoking in the past 6 months, were married or were living with a partner, and were willing to offer their telephone contact information. All participating women gave written consent for contact, and subsequently gave verbal informed consent for participation in the study. Ethical approval was obtained from the Michigan State University Institutional Review Board (IRB\# 14-910).

\section{Data collection}

All eligible women who expressed interest in participating, by filling in the consent form for contact, were contacted by telephone by a researcher (female interviewer, graduate research assistant) within 2 weeks. The researcher further explained study procedures, obtained verbal consent for participation, and conducted the interviews via telephone. After finalizing the interview, a short list of questions were asked on socio-demographics, smoking behavior and interaction with partner 
in smoking cessation. Interviews were conducted between November 2015 and April 2016, each lasting 30-50 minutes, and recruitment was ceased when data saturation was reached. All reported interviews were audio-recorded with the permission of the participants, and transcribed verbatim for analysis. Women participating in the study were offered a gift voucher for a prenatal course (about $\$ 20$ ). No repeat interviews were conducted, and transcripts were not returned for comments to the study participants, as all aspects were clarified during the interviews.

A semi-structured interview guide was used that covered the following topics: smoking narratives, experience with smoking and smoking cessation (including smoking history and quit attempts), commitment to remain smoke free (for former smokers), relationship with the partner (including types of interactions regarding smoking, teamwork standards, dyadic efficacy, and coping), and support for smoking cessation. A second part of the interview covered details of a planned Randomized Controlled Trial (RCT) - results not reported here.

\section{Data analysis}

Transcripts were anonymized and analyzed using NVivo11-assisted thematic analysis. A hybrid inductive-deductive approach was used, to identify patterns in the data and to explore the women's narratives, in relation to smoking and smoking cessation. Any cases or accounts that distanced themselves from the main experiences were also given increased attention, to ensure integrity of the findings. A selection of transcripts was initially read by two of the co-authors (AB and AS) and annotated; after discussing an initial coding scheme, the two coauthors independently coded the data. Codes were re-structured after a first round of coding, grouped into categories and reorganized where needed. Intercoder reliability was assessed periodically, rendering high coding consistency. Emerging themes were then explored in depth, by subsequent coding and mapping on the transcripts.

A set of deductive codes was used in the analysis to explore the way couples deal with smoking cessation together as a dyad: teamwork standards (the extent to which women consider that smoking cessation needs to be dealt with as a team or individually) ${ }^{17}$; dyadic efficacy (the perceived ability to deal with the difficulties of smoking together as a couple $)^{17}$; dyadic coping (the mechanisms the couple employs to deal with the difficulties of smoking cessation) $)^{18}$; and partner interaction (the positive and negative interactions women experience with their partners, regarding smoking and the process of quitting smoking $)^{19}$. These codes were used in conjunction with inductive codes, to analyze women's narratives and to support the description of different dynamics within couples.

\section{RESULTS}

In the clinic where most of the participants were recruited, and where we had complete information, the refusal rate among potentially eligible participants was approximately $25.5 \%$. A total of 60 women expressed interest in participating in the study by signing a consent form for contact. Of these, 7 had given birth by the time they were contacted, 15 could not be contacted at all, and 21 interviews were repeatedly scheduled but could not be conducted as they were postponed indefinitely. The remaining 17 women were enrolled in the study and interviewed. Two interviews could not be used in the current analysis due to technical problems with audio-recording, and no transcripts were available for them. The sociodemographic characteristics and smoking behavior of the 15 women included in the analyses ( 7 smokers and 8 former smokers), can be found in Table 1 . The average age within the sample was of 30.3 years, and the average gestation age was 22.6 weeks. Seven women were primigravida. Most interviewed women had attained a university degree $(n=11)$, while four had high-school education. The average relationship length was of 5.6 years, and 10 women were living with a smoker partner.

Within our analysis, several themes emerged from the data, which reflect barriers to and facilitators of quitting smoking during pregnancy. We focused on three main themes, which shaped the socio-cultural adaptation of the Quit Together intervention to the local context: 1) Access to and mixed messages from the healthcare system, 2) Cessation as individual or team effort, and 3) Transition to motherhood and motivation to quit.

\section{Theme 1: Access to and mixed messages from the healthcare system}


Table 1. Sociodemographic characteristics and smoking status

\begin{tabular}{|c|c|}
\hline & Vean (SD) Number $(\%)$ \\
\hline Maternal age in years $(\mathrm{M}, \mathrm{SD})$ & $30.3(3.7)$ \\
\hline \multicolumn{2}{|l|}{ Residence $(n, \%)$} \\
\hline Urban & $8(53.3 \%)$ \\
\hline Rural & $7(46.7 \%)$ \\
\hline \multicolumn{2}{|l|}{ Education $(n, \%)$} \\
\hline High-school & $4(26.7 \%)$ \\
\hline University degree & $11(73.3 \%)$ \\
\hline \multicolumn{2}{|l|}{ Primigravida (n, \%) } \\
\hline Yes & $7(46.7 \%)$ \\
\hline No & $8(53.3 \%)$ \\
\hline Gestation in weeks (M, SD) & $22.6(8.9)$ \\
\hline \multicolumn{2}{|l|}{ Smoking status (n, \%) } \\
\hline Smoker & $7(46.7 \%)$ \\
\hline Quit & $8(53.3 \%)$ \\
\hline \multicolumn{2}{|l|}{ Partner smoking status (n, \%) } \\
\hline Smoker & $10(66.7 \%)$ \\
\hline Quit & $4(26.7 \%)$ \\
\hline Never smoker & $1(6.6 \%)$ \\
\hline Relationship length in years (M, SD) & $5.5(3.4)$ \\
\hline
\end{tabular}

Most women acknowledged the importance of discussing smoking and smoking cessation with their practitioners, but described a variety of interactions with the healthcare system. Some women did not discuss smoking with healthcare providers, while others had difficulties in accessing their healthcare providers.

'Honestly, I haven't discussed smoking with my family physician or any other doctor. Really I haven't. Yes, we have talked about other problems, but not about smoking'. (1050, smoker, highschool education)

'I would like to talk to her (GP) but she is not answering my phone calls (...) and even when she does, she rushes me off, quickly-quickly (...) and usually when we go over for a consult, she consults me and that's it; you can't possibly exchange a word with her'. (1045, smoker, high-school education)

Other women described having discussions regarding smoking and smoking cessation with healthcare providers, but the messages they received were mixed. Some explained that physicians encouraged them to quit smoking and clarified the risks of smoking during pregnancy. Others reported that healthcare professionals encouraged harm-reduction strategies (to reduce the number of cigarettes).

'I have asked him what risks carry children who are born from smoker mothers and non-smoker mothers... and he told me that they are born smaller, some forget to breath (...) he described all kind of risks and he told me that I should better quit smoking'. (1053, ex-smoker, graduate education)

'We have discussed it, but how should I put it... at a superficial level. He (physician) asked if I smoke or if I had smoked and quit (...) or if I have quit and I feel the need to, and if I want to smoke, or if I am craving or want to enjoy a cigarette, I should do it, if I really want to'. (1016, ex-smoker, postgraduate education)

One woman recalled a discussion she had had with her obstetrician during her previous pregnancy (two years before), who advised her to reduce the number of cigarettes smoked, but only to the point where it was not emotionally distressing. The woman described the physician's advice that it was acceptable to have a few puffs when needed, to avoid depression.

'I know that during my first pregnancy, he told me it would be very good if I quit smoking but he said: I don't want you to do it at any cost; if you really feel the need to light up a cigarette and have three puffs, I mean instead of being depressive, if you really feel the need, light up a cigarette; but try to reduce them if you can't completely quit smoking'. (1041, smoker, graduate education)

Within the smoking reduction discourse, a recurrent acceptable threshold of five smoked cigarettes emerged, from the women's narratives, as being inferred by some healthcare providers. One interviewee even discussed a potential 'tolerance threshold' that some healthcare practitioners had, which defines how much a woman could smoke during pregnancy.

'Actually, opinions are diverse; some physicians say it's alright to smoke one cigarette, maybe two, up to five, while other physicians tell you not to smoke at all'. (1005, smoker, undergraduate education) 'I know out of experience that doctors don't discourage smoking completely; they have a 
tolerance threshold (...) I have talked to him (gynecologist) about this: if I could reduce them under five it would be alright; complete quitting would be ideal but not necessarily essential'. (1025, ex-smoker, graduate education)

This was reported by women from their direct interaction with healthcare providers, but also the five acceptable cigarettes suggestion was reported in other women's discourses. One interviewee described the same narratives from other pregnant women sharing their experiences on web forums.

'The girls were writing on the forums that the doctor told them that they can smoke up to 5 cigarettes per day, the light kind'. (1018, exsmoker, undergraduate education)

In terms of preferences for discussing smokingrelated issues, some women reported having a closer relationship with the general practitioner (family physician), while others had better communication regarding smoking cessation with their obstetrician. In one account, when asked if she had discussed smoking cessation with her family physician, one woman reported that 'the family physician smokes in his office' (1024, smoker, undergraduate education).

\section{Theme 2: Cessation as individual or team effort}

Some partners engaged significantly in helping their women to cope with the difficulties of smoking cessation, and these women also described valuing teamwork towards smoking cessation more. They described interaction from minimal involvement (minimal advice to quit or reduce smoking) to more intense employment of dyadic coping strategies.

'He (partner) always tells me: It's not good, it's not good for us; it would be better for all of us if you stop smoking (...) When I would say: Oh, I would really need a cigarette (he would say): Let's go have a juice or Let's eat some seeds. He was next to me all along, telling me Come on, you have the strength, he would encourage me saying You can do this, you definitely can do this (...) It would be a couple's breakthrough if I would succeed (in quitting smoking)'. (1021, smoker, undergraduate education)

Other women expressed ambivalence in dyadic efforts, either by changing their discourse throughout the interview, or by acknowledging the importance of the partner's decision, but emphasizing the independent process of individually making a cessation decision.

'It's rather important in any couple (partner's involvement) (...) But honestly, for me it's not the case... in my case, smoking is a foolish ambition. That's it. And it's not the case for him to tell me or to... it's just a foolish vice. I know it's not doing me any good but... (...) I don't need anyone helping me (...) when I acknowledge it in my mind that it's not right, then I will quit'. (1050, smoker, highschool education)

'His decision is important too, but like I said, it depends on the respective person how ambitious she is. First of all, I need to have the ambition to quit, and not have anyone forcing me to do it'. (1052, smoker, graduate education)

In other cases, smoking cessation was viewed by women as an individual effort. This was the situation of women who reported quitting with little effort, which translated into a very low involvement from the partner.

'It wasn't a difficult decision. I mean it was natural and normal. No, I didn't spend too much time thinking about it (...) I don't know how the mind of an addicted person works, but in my case, it probably wasn't an addiction (...) (after learning about the pregnancy) there wasn't the case for him telling me anything, because I just stopped smoking (...) but there was never the case of a team'. (1042, ex-smoker, graduate studies)

The partner's own smoking behavior was described in some cases as relevant, with regards to his legitimacy in intervening in the woman's smoking cessation attempt. One woman discussed the fact that non-smoker partners cannot support smoking women in their cessation attempt as effectively as smoker partners.

'A non-smoker could not do anything about it. Unless he imposes himself, I don't know, using fear, on an emotional level or emotional blackmail, or things like this... a non-smoker cannot help you otherwise (...) a smoker could motivate you when you see that they don't light up a cigarette, and 
then you can't light your own... You can't allow yourself to do that, if that other person is trying to quit and you would see that they are making a real effort to support you; in turn, you would probably feel in one way or another obliged not to smoke'. (1024, smoker, undergraduate education)

\section{Theme 3: Transition to motherhood and motivation to quit}

Women in our interviewed group discussed the changes in motivation in quit attempts during pregnancy compared to other quit attempts. The primary motivation emerging from women's discourses was child health as the central element.

'For me it was a lot more important to... to think that I want to have a healthy child, even though this thought, especially in the case of a first pregnancy, is a thought that every woman has'. (1008, exsmoker, postgraduate studies)

This discourse was found as a pattern throughout the data, however two specific cases distanced themselves from the rest of the interviews. One woman had previously gone through a miscarriage. Throughout the interview, she had expressed similar motivation to quit smoking both for the health of the baby and for the pregnancy itself. However, she also expressed guilt and responsibility towards her husband regarding the miscarriage, and the need to 'clean' her body in order to take a second pregnancy to term. She described this experience as identityaltering, as she can now self-identify with a nonsmoker, whereas earlier she could not.

'I have had previous quit attempts, but I didn't have the willpower. It was in vain. I didn't see myself as a non-smoker (...) I perceived the lack of smoking as something that was missing; it felt like someone had taken a friend away (laughs) (...) This time I had willpower and the need to boost up my confidence (...) And the presence of a little child in your belly, I say that's a reason that no one has to bother to tell you about it. You need to realize that and be pleased that you, as a mother, have done everything possible not to affect the baby (...) if anything happens, God forbid, at least I have a clean conscience that I have done everything in my power, gave up everything harmful; not to have disagreements with the husband, have things thrown to your face: You lost the pregnancy because you smoked or You have these complications because you smoked'. (1018, ex-smoker, undergraduate studies)

The second case was of a mother who discussed how she had difficulties in adjusting to the role of a mother, as nothing had changed in her life up to that point. She reported no morning sickness, and no clear signs of her life changing due to the pregnancy. She discussed this as being relevant to continuing smoking during pregnancy.

'It depends on how each person interprets the pregnancy, how they take on the role of a parent at that time and so on (...) in the sense that there are some persons who upon learning about the pregnancy, it means everything to them and nothing else exists on this planet, and they are capable of any sacrifices for that child; others don't even realize it, nothing changes in their life up to the point they get to hold their baby in their arms. In this latter situation, I find myself (...) anything else besides my belly growing and something moving inside and you clearly know there's something in there... I probably won't be fully aware of it until they will place the baby in my arms'. (1024, smoker, undergraduate education)

A sub-theme emerging from this data relates to health beliefs regarding smoking, and the timing of smoking cessation. As previously, respondents talked about 'cleaning' one's body before the pregnancy; these concepts of an individual's body also emerged in connection with a potential 'too late to quit' situation.

'for me to quit and for everything to be ok, I should have quit a longer time ago, for my body to be, as they say, detoxified of nicotine, some time before becoming pregnant'. (1050, smoker, high-school education)

\section{DISCUSSION}

This study provides new insights on contextdependent barriers to and facilitators of smoking cessation during pregnancy, in a middle-income former communist country. They highlight systemic barriers to effective smoking cessation, as well as the relevance of diverse partner interactions in the 
efforts to quit. The findings emphasize the need to understand in depth women's experiences when developing tailored intervention programs, especially in under-researched settings. The present study contributes to the existing body of knowledge, by illustrating how qualitative findings can be translated in the socio-cultural adaptation of health programs. Three main levels were discussed, from structural determinants such as the healthcare system, to partner dynamics and interaction, and ultimately to individual-level factors (motivations to quit and transition to motherhood). Even though the manuscript does not exhaustively discuss all the barriers and facilitators identified in women's narratives, it highlights the ones most relevant in tailoring a couple-based intervention to reduce smoking during pregnancy. The strengths of this study reside in the couple-based approach for understanding smoking and cessation behavior in pregnant women; also, the study included both smokers as well as spontaneous quitters. The main limitation of the study relies in the recruitment strategy, which allowed the enrollment only of women who attended prenatal care (as recruitment was conducted in clinical settings). Another potential limitation of the study is the lack of data on the level of nicotine dependence. It is possible that different themes may emerge in qualitative studies of highly dependent smokers compared to studies of lightly addicted smokers.

Women's narratives regarding their interaction with the healthcare system suggest that the support they receive is sometimes fragmented, and that there is an inconsistent discourse towards smoking cessation during pregnancy coming from the healthcare system. The recurrent number of 'up to five' acceptable cigarettes suggests that there is a degree of misconception regarding the health effects of smoking during pregnancy, as there is no documented safe limit for smoking during pregnancy. Evidence suggests that even light smokers (up to 5 cigarettes per day) are at increased risk for low birth weight ${ }^{20}$. The literature does acknowledge that cutting down on smoking can be an alternative to quitting smoking in very difficult domestic circumstances, where cessation is hard to achieve $^{21}$. However, there was no evidence that the women in our sample, who had reported that health professionals condoned cutting down, were subject to difficult socioeconomic and domestic circumstances. It is essential that the health system recognizes and promotes the benefits of cessation, and does not convey that there is a lower risk associated with a reduced consumption of tobacco products. The Quit Together program addresses this, and other misconceptions, by incorporating a module on myths and misconceptions on smoking during pregnancy in the intervention material and the interventionists' training.

Women's preferences in discussing smoking cessation were diverse, with some preferring interacting with obstetricians while others with family physicians on this matter. Evidence suggests that even brief opportunistic advice, offered in medical settings, has a significant effect on smoking cessation $^{22}$. However, some women in our study did not discuss the risks of smoking with any health professional. Studies conducted in Europe suggest that there is great diversity regarding GPs involvement in smoking cessation. This diversity is contingent on several factors, among which are the smoking behavior of the GPs, their attitudes towards smoking, reservations regarding inducing anxiety or guilt among pregnant women, but also self-confidence in providing cessation support ${ }^{23}$. A qualitative study involving family physicians (general practitioners) in Romania suggested that they generally feel untrained to offer smoking cessation support, emphasizing the need to integrate appropriate training in their professional development ${ }^{24}$. More research should be conducted to assess the capacity of the healthcare system to effectively offer support to pregnant women in their cessation attempt. The Quit Together project explores the potential of the intervention to be embedded in smoking cessation programs that include quit-lines.

Pregnant women who report increased dyadic efficacy in smoking cessation are more likely to successfully quit smoking ${ }^{17}$. Partner interactions described by the women in our study ranged across teamwork standards, dyadic coping and dyadic efficacy. However, the smoking status of the partner could also be an important factor. Recent studies on smoking-concordant and smoking-discordant couples suggest that smokers who have a smoker partner are more likely to prefer their partner's 
involvement in smoking cessation programs ${ }^{25}$. This diversity should be accounted for in a smoking cessation intervention, to tailor it to the needs of such a heterogeneous group. Women narrating more intense dyadic efficacy and dyadic coping practices, also viewed teamwork standards as more relevant. A possible limitation of the proposed intervention is the difficulty reaching women who have low teamwork standards and dyadic practices, as they may be less likely to agree to enroll and refer their partner to be enrolled in the intervention. Future studies should explore involving subsequently the partner in the woman's engagement in the intervention, as the woman builds the skills to engage the partner. Alternatively, for women reporting low value in partner involvement, future designs could explore delivering the intervention to women alone or involving other relevant support people (e.g. friends, siblings, parents).

Women's motivations to quit are diverse, as described in their narratives. Even though most women decide to quit smoking for the pregnancy and the health of the child, some women had difficulties achieving this. Smoking cessation interventions should be more sensitive to diverse perspectives and experiences of pregnant smokers. Recent literature suggests that a more woman-centered, transformative approach to smoking cessation should extend the existing fetalcentered approaches, which are less sustainable ${ }^{26}$. From the perspective of the Quit Together intervention, this finding supported delivering smoking cessation counseling in the wider context of women's health, using a Wellness Plan. In this context, women can choose to set wellness goals, directly or indirectly associated with smoking, to identify effective strategies to support smoking cessation.

\section{CONCLUSIONS}

This study provides new insights on context-dependent barriers to and facilitators of smoking cessation during pregnancy, in a middle-income former communist country. They highlight systemic barriers to effective smoking cessation, as well as the relevance of diverse partner interactions in the efforts to quit. The study also shows how women's experiences and perspectives can effectively inform the development and adaptation of public health interventions, in under-researched social environments.

\section{REFERENCES}

1. Goldenberg R, Culhane J, Iams J, Romero R. Epidemiology and causes of preterm birth. Lancet 2008;371(9606):75-84.

doi:10.1016/S0140-6736(08)60074-4

2. Keegan J, Mehdi P, Mark F, Andrew G, Michael B. Addiction in Pregnancy. J. Addict. Dis. 2010;29(2):175191. doi:10.1080/10550881003684723

3. Mund M, Louwen F, Klingelhoefer D, Gerber A. Smoking and Pregnancy - A Review on the First Major Environmental Risk Factor of the Unborn. Int. J. Environ. Res. Public Health 2013;10(12):6485-6499. doi:10.3390/ijerph10126485

4. Abraham M, Alramadhan S, Iniguez C, et al. A systematic review of maternal smoking during pregnancy and fetal measurements with meta-analysis. Niaura R, ed. PLoS One 2017;12(2):e0170946.

doi:10.1371/journal.pone.0170946

5. Lee LJ, Lupo PJ. Maternal Smoking During Pregnancy and the Risk of Congenital Heart Defects in Offspring : A Systematic Review and Metaanalysis. Pediatr. Cardiol. 2012;34:398-407. doi:10.1007/s00246-012-0470-x

6. National Center for Chronic Disease Prevention and Health Promotion (US) Office on Smoking and Health. The Health Consequences of Smoking - 50 Years of Progress A Report of the Surgeon. Atlanta, GA; 2014.

7. World Health Organization. Empower Woman Combating Tobacco Industry Marketing in the WHO European Region. Copenhagen; 2010.

8. Smedberg J, Lupattelli A, Mårdby A-C, Nordeng H. Characteristics of women who continue smoking during pregnancy: a cross-sectional study of pregnant women and new mothers in 15 European countries. BMC Pregnancy Childbirth 2014;14:213.

doi:10.1186/1471-2393-14-213

9. Blaga OM, Brinzaniuc A, Rus IA, Cherecheș RM, Wallis AB. Smoking and Smoking Cessation During Pregnancy. An Analysis of a Hospital Based Cohort of Women in Romania. J. Community Health 2017;42(2):333-343. doi:10.1007/s10900-016-0259-6

10. Flemming K, McCaughan D, Angus K, Graham H. Qualitative systematic review: barriers and facilitators to smoking cessation experienced by women in pregnancy and following childbirth. J. Adv. Nurs. 2015;71(6):12101226. doi:10.1111/jan.12580

11. Bauld L, Graham H, Sinclair L, et al. Barriers to and facilitators of smoking cessation in pregnancy and following childbirth: literature review and qualitative study. Health Technol. Assess. (Rockv). 2017;21(36):1158. doi:10.3310/hta21360

12. Flemming K, Graham H, Heirs M, Fox D, Sowden A. Smoking in pregnancy: a systematic review of qualitative research of women who commence pregnancy as smokers. J. Adv. Nurs. 2012;65(5):1023-1036.

doi:10.1111/jan.12066 
13. ClinicalTrials.gov - Family Smoking Cessation in Romania Using Pregnancy as a Window of Opportunity (QuitTogether). https://clinicaltrials.gov/ct2/show/ NCT02512913. Accessed August 5, 2017.

14. Dubois J-L. Reinforcing households' capabilities as a way to reduce vulnerability and prevent poverty in equitable terms. In Comin F. (ed.), Qizilbash M. (ed.), Alkire S. (ed.) The capability approach: concepts, measures and applications. Cambridge: Cambridge University Press; 2008:421-436

15. Hinote BP, Cockerham WC, Abbott P. Post-Communism and Female Tobacco Consumption in the Former Soviet States. Eur. Asia. Stud. 2009;61(9):1543-1555. doi:10.1080/09668130903209129

16. Tong A, Sainsbury P, Craig J. Consolidated criteria for reporting qualitative research (COREQ): a 32-item checklist for interviews and focus groups. Int. J. Qual. Heal. care 2007;19(6):349-357 https://doi.org/10.1093/intqhe/mzm042

17. Sterba KR, Ph D, Rabius V, et al. Dyadic Efficacy for Smoking Cessation : Preliminary Assessment of a New Instrument. Nicotine Tob. Res. 2011;13(3):194-201. doi:10.1093/ntr/ntq236

18. Bodenmann G. Dyadic coping: A systemic-transactional view of stress and coping among couples : Theory and empirical findings. Rev. Eur. Psychol. Appl. 1997;47(2):137-140.

19. Cohen S, Lichtenstein E. Partner behaviors that support quitting smoking. J. Consult. Clin. Psychol. 1990;58(3):304-309. doi:10.1037/0022-006X.58.3.304

20. Ventura SJ, Hamilton BE, Mathews TJ, Chandra A. Trends and variations in smoking during pregnancy and low birth weight: evidence from the birth certificate, 1990-2000. Pediatrics 2003;111(5 Pt 2):1176-80.

21. Graham H, Flemming K, Fox D, Heirs M, Sowden A. Cutting down: insights from qualitative studies of smoking in pregnancy. Health Soc. Care Community 2014;22(3):259-267. doi:10.1111/hsc.12080

22. Aveyard P, Begh R, Parsons A, West R. Brief opportunistic smoking cessation interventions: a systematic review and meta-analysis to compare advice to quit and offer of assistance. Addiction 2012;107(6):1066-1073. doi:10.1111/j.1360-0443.2011.03770.x

23. Stead M, Angus K, Holme I, Cohen D, Tait G, PESCE European Research Team. Factors influencing European GPs' engagement in smoking cessation: a multi-country literature review. Br. J. Gen. Pract. 2009;59(566):682690. doi:10.3399/bjgp09X454007

24. Panaitescu C, Moffat MA, Williams S, et al. Barriers to the provision of smoking cessation assistance: a qualitative study among Romanian family physicians. NPJ Prim. care Respir. Med. 2014;24:14022. doi:10.1038/npjpcrm.2014.22

25. Tooley EM, Borrelli B. Characteristics of cigarette smoking in individuals in smoking concordant and smoking discordant couples. Couple Fam. Psychol. Res. Pract. 2017;6(2):106-116. doi:10.1037/cfp0000078.

26. Greaves L, Hemsing N, Poole N, et al. From fetal health to women's health: expanding the gaze on intervening on smoking during pregnancy. Crit. Public Health $2014 ; 26(2): 230-238$.

doi:10.1080/09581596.2014.968527
ACKNOWLEDGEMENTS

The authors are grateful to the participants, staff and health providers involved in the Quit Together study.

\section{CONFLICTS OF INTEREST}

Authors have completed and submitted the ICMJE Form for Disclosure of Potential Conflicts of Interest and none was reported.

\section{FUNDING}

This work was supported by the Fogarty International Center of the National Institutes of Health under Award Number K01TW009654. The content is solely the responsibility of the authors and does not represent the official views of the funder.

PROVENANCE AND PEER REVIEW

Not commissioned; externally peer reviewed 